\section{REFERENCES}

1 Global Initiative for Chronic Obstructive Lung Disease. Global Strategy for Diagnosis, Management, and Prevention of COPD. Updated 2010. www.goldcopd.com Date last accessed: March 18, 2011.

2 Geijer RM, Sachs AP, Verheij TJ, et al. Incidence and determinants of moderate COPD (GOLD II) in male smokers aged 40-65 years: 5-year follow up. Br J Gen Pract 2006; 56: 656-661.

3 Qaseem A, Snow V, Shekelle P, et al. Diagnosis and management of stable chronic obstructive pulmonary disease: a clinical practice guideline from the American College of Physicians. Ann Intern Med 2007; 147: 633-638.

4 Enright P, Brusasco V. Counterpoint: Should we abandon FEV1/ FVC $<0.70$ to detect airway obstruction? Yes. Chest 2010; 138: 1040-1042.

5 Mannino DM, Buist AS, Vollmer WM. Chronic obstructive pulmonary disease in the older adult: what defines abnormal lung function? Thorax 2007; 62: 237-241.
6 Vaz Fragoso CA, Concato J, McAvay G, et al. The ratio of forced expiratory volume in 1-second to forced vital capacity as a basis for establishing chronic obstructive pulmonary disease. Am J Respir Crit Care Med 2010; 181: 446-451.

7 Vaz Fragoso C, Gill T, McAvay G, et al. Evaluating respiratory impairment in middle-aged persons using lambda-mu-sigma derived z-scores. Respir Care 2011; (In press).

8 Bridevaux PO, Gerbase MW, Probst-Hensch NM, et al. Long-term decline in lung function, utilisation of care and quality of life in modified GOLD stage 1 COPD. Thorax 2008; 63: 768-774.

9 Vollmer WM, Gíslason B, Burney $\mathrm{P}$, et al. Comparison of spirometry criteria for the diagnosis of COPD: results from the BOLD study. Eur Respir J 2009; 34: 588-597.

10 Miller MR, Quanjer PH, Swanney MO, et al. Interpreting lung function data using $80 \%$ predicted and fixed thresholds misclassifies more than $20 \%$ of patients. Chest 2011; 139: 52-59.

DOI: $10.1183 / 09031936.0006321$

\title{
COPD: an autoimmune disease?
}

\section{To the Editors:}

HEMMINKI et al. [1] report an increased prevalence of chronic obstructive pulmonary disease (COPD) in patients with autoimmune disease and suggest the presence of autoimmunity is a risk factor for the development of COPD. We have previously reported an increased prevalence of autoimmune disease in patients with COPD who have never smoked [2]. These patients tended to be elderly females and many had a blood lymphopenia, positive autoantibodies and airway inflammation. We have also reported a four-fold increase in the prevalence of COPD in patients with autoimmune bowel disease $[3,4]$. The association with autoimmune disease is not limited to COPD; patients with unexplained chronic cough (UCC) are eight times more likely to have autoimmune disease compared to matched controls [5]. Patients with UCC are largely middle-aged females and have evidence of lymphocytic airway inflammation [6]. The mechanism for the association of cough with airway lymphocytosis may be homing of inflammation from the primary site of autoimmune disease to the airways [7]. A recent study has reported that patients with UCC have an increased decline in lung function, which raises the possibility that some patients with UCC may develop COPD [8].

It is likely that the presence of factors other than smoking is necessary for the development of COPD since most smokers do not develop COPD [9]. Examples of co-factors include autoimmunity and chronic airway infection. Further studies should investigate whether therapy targeting co-factors could prevent or treat COPD.

\section{S.S. Birring* and I.D. Pavord ${ }^{\#}$}

*Division of Asthma, Allergy and Lung Biology, King's College London, London, and "Institute for Lung Health, Dept of Respiratory Medicine, Glenfield Hospital, Leicester, UK.
Correspondence: S.S. Birring, King's College London, Division of Asthma, Allergy and Lung Biology, Denmark Hill, London SE5 9RS, UK. E-mail: surinder.birring@nhs.net

Statement of Interest: None declared.

\section{REFERENCES}

1 Hemminki K, Liu X, Ji J, et al. Subsequent COPD and lung cancer in patients with autoimmune disease. Eur Respir J 2011; 37: 463-465.

2 Birring SS, Brightling CE, Bradding P, et al. Clinical, radiologic, and induced sputum features of chronic obstructive pulmonary disease in nonsmokers: a descriptive study. Am J Respir Crit Care Med 2002; 166: 1078-1083.

3 Raj AA, Birring SS, Green R, et al. Prevalence of inflammatory bowel disease in patients with airways disease. Respir Med 2008; 102: 780-785.

4 Birring SS, Morgan AJ, Prudon B, et al. Respiratory symptoms in patients with treated hypothyroidism and inflammatory bowel disease. Thorax 2003; 58: 533-536.

5 Birring SS, Murphy AC, Scullion JE, et al. Idiopathic chronic cough and organ-specific autoimmune diseases: a case-control study. Respir Med 2004; 98: 242-246.

6 Birring SS, Brightling CE, Symon FA, et al. Idiopathic chronic cough: association with organ specific autoimmune disease and bronchoalveolar lymphocytosis. Thorax 2003; 58: 1066-1070.

7 Birring SS, Patel RB, Parker D, et al. Airway function and markers of airway inflammation in patients with treated hypothyroidism. Thorax 2005; 60: 249-253.

8 Yousaf N, Birring SS, Pavord ID. Long term outcome of patients with unexplained chronic cough. Thorax 2009; 64: S25.

9 Pavord ID, Birring SS, Berry M, et al. Multiple inflammatory hits and the pathogenesis of severe airway disease. Eur Respir J 2006; 27: 884-888. 